http://nv.nltu.edu.ua

https://doi.org/10.15421/40280229

Article received 21.03.2018 $\mathrm{p}$.

Article accepted 29.03.2018 p.

удк 004.75
ISSN 2519-2477 (online)

(c) (1)

@ Correspondence author

T. H. Tsavolyk

calisto2292@ukr.net

Т. Г. Цаволик, В. В. Яцків

Тернопільський національний економічний університет, м. Тернопіль, Украӥна

\title{
ВИПРАВЛЕННЯ ПАКЕТІВ ПОМИЛОК НА ОСНОВІ МОДУЛЯРНОГО КОРИГУВАЛЬНОГО КОДУ
}

\begin{abstract}
Запропоновано метод виправлення пакетів помилок на основі модулярного коригувального коду для підвищення надійності передачі даних у безпровідних сенсорних мережах. Для боротьби з пакетами помилок розроблено різні багатовимірні (каскадні, ітеративні) коди. Принцип роботи цих кодів полягає в послідовному використанні двох рівнів кодування і декодування даних. При цьому на кожному рівні кодування можна використовувати однакові за типом і коригувальною здатністю коди або різні. Перевагою багатовимірних кодів $\epsilon$ їх висока коригувальна здатність, а недоліком - висока надлишковість. Розроблено двовимірну схему контролю помилок на основі модулярного коригувального коду. Модулярні коригувальні коди належать до символьних кодів, характеризуються низькою надлишковістю, дають змогу ефективно виявляти та виправляти одиничні символьні помилки. Принцип формування перевірних символів у двовимірному модулярному коді полягає в такому: спочатку обчислюють перевірні символи по рядках матриці даних; на наступному кроці обчислюють перевірні символи по стовпцях даних. Розроблено алгоритм виявлення та виправлення випадкових однократних помилок та пакетів помилок максимальною довжиною $b=3 k-2$. Проведено експериментальні дослідження з виявлення та виправлення помилок у пакеті даних. Показано мінімальну та максимальну довжину та структуру помилок, яку може виправити цей код. Враховуючи низьку складність реалізації алгоритму декодування, цей коригувальний код планують використати для підвищення надійності передачі даних у безпровідних сенсорних мережах.
\end{abstract}

Ключові слова: модулярні коригувальні коди; безпровідні сенсорні мережі; двовимірний код; пакет помилок.

Вступ. У сучасних безпровідних каналах зв'язку, окрім одиничних помилок, спричинених шумами, часто трапляються пакети помилок, викликані імпульсними перешкодами або завмираннями (Alrajeh, et al., 2015; Aditya, 2014; Yatskiv, et al., 2013). При цьому можуть бути спотворені десятки, а то й сотні біт інформації підряд. Для боротьби з пакетами помилок розроблено багатовимірні коди (каскадні, ітеративні коди, коди-добутку) (Fatt et al., 2014). Ідея створення ітеративних кодів належить П. Елайесу (Elias) (Bleikhut, 1986). Суть цього методу кодування полягає у використанні декількох рівнів кодування і декодування даних (Yatskiv et al., 2014). При цьому на кожному рівні кодування можна використовувати однакові за типом і коригувальною здатністю коди або різні. Перевагою багатовимірних (каскадних, ітеративних) кодів є висока коригувальна здатність, а недоліком - висока надлишковість (Morelos-Saragosa, 2005).

Модулярні коригувальні коди, що розроблено в (Yatskiv et al., 2013; Jun \& Yatskiv, 2013), належать до символьних кодів, характеризуються низькою надлишковістю та дають змогу ефективно виявляти та виправляти одиничні символьні помилки. У роботі (Sieck et al., 2015) показано можливість побудови двовимірних коригувальних кодів на основі модулярної арифметики, які допомагають виявляти та виправляти помилки у двох і більше інформаційних символах. Проте запропонований метод виправлення помилок у двох символах на основі розширеного алгоритму Евкліда має високу часову складність, яка залежить від величини модуля $P$ і зростає із збільшенням кількості та розрядності інформаційних символів, оскільки потребує знаходження всіх розв'язків діафантового рівняння. Також потребують додаткових досліджень алгоритми виправлення пакетів помилок. Отже, актуальною науковою задачею є розробки багатовимірного (ітеративного) методу кодування коду на основі модулярного коригувального коду та алгоритмів виправлення пакетів помилок.

Мета роботи - підвищення ефективності виявлення і виправлення пакетів помилок на основі модулярного коригувального коду.

Модулярний двовимірний код. Двовимірним кодом $y=y_{1} \times y_{2}$ двох кодів $y_{1}$ i $y_{2}$ називають код, кодовими словами якого $\epsilon$ всі двовимірні таблиці з рядками, які $\epsilon$ словами коду $y_{1}$ і стовпцями, які є словами коду $y_{2}$.

Як коди $y_{1}$ i $y_{2}$ для побудови двовимірного коду вибрано модулярний коригувальний код (Jun \& Yatskiv, 2013). При цьому коди можуть буди як однакові $y_{1}=y_{2}$, так і різні $y_{1} \neq y_{2}$.

У модулярному коригувальному коді перевірні символи обчислюють:

Інформація про авторів:

Цаволик Тарас Григорович, аспірант, викладач кафедри кібербезпеки. Email: calisto2292@ukr.net

Яцків Василь Васильович, д-р техн. наук, доцент, завідувач кафедри кібербезпеки. Email: jazkiv@ukr.net

Цитування за ДСтУ: Цаволик Т. Г., Яцків В. В. Виправлення пакетів помилок на основі модулярного коригувального коду. Науковий вісник НЛтУ України. 2018, т. 28, № 2. С. 155-159.

Citation APA: Tsavolyk, T. H., \& Yatskiv, V. V. (2018). Burst Error-Correcting Codes Based on Modular Correcting Codes. Scientific Bulletin of UNFU, 28(2), 155-159. https://doi.org/10.15421/40280229 


$$
\begin{aligned}
& f_{j k}(x)=\sum_{i=1}^{k} x_{i j} v_{j} \bmod P, j=\overline{1, l}, \\
& f_{l i}(x)=\sum_{j=1}^{l} x_{j i} v_{i} \bmod P, i=\overline{1, k},
\end{aligned}
$$

де: $x_{j i}-$ інформаційні символи, $v_{i}, v_{j}$ - коефіцієнти (прості числа), $P$ - просте число.

Формування двовимірного модулярного коду наведено в табл. 1. Спочатку кодом $y_{1}$ кодується кожний із $l$ рядків, а потім кодом $y_{2}-$ кожний із $k$ стовпців.

\begin{tabular}{|c|c|c|}
\hline & Інформаційний символ & \# \\
\hline & $\begin{array}{rrrrrr}x_{11} & x_{12} & \ldots & x_{1 i} & \ldots & x_{1 k} \\
x_{21} & x_{22} & \ldots & x_{2 i} & \ldots & x_{2 k} \\
\ldots & \ldots & \ldots & \ldots & \ldots \\
x_{j 1} & x_{j 2} & \ldots & x_{j i} & \ldots & x_{j k} \\
\ldots & \ldots & \ldots & \ldots & \ldots & \ldots \\
x_{l 1} & x_{l 2} & \ldots & x_{l i} & \ldots & x_{l k}\end{array}$ & $\begin{array}{c}f_{1 k}(x) \\
f_{2 k}(x) \\
\ldots \\
f_{j k}(x) \\
\ldots \\
f_{l k}(x) \\
\end{array}$ \\
\hline \#\# & $f_{l 1}(x) \quad f_{l 2}(x) \quad \ldots f_{l i}(x) \quad \ldots f_{l k}(x)$ & \\
\hline
\end{tabular}

Табл. 1. Формування двовимірного модулярного коду

Примітка: перевірні символи по рядках (\#) і стовпцях (\#\#).

Процес кодування полягає у такому (рис. 1): дані по $k$ символів поступають у внутрішній кодер $y_{1}$, де обчислюють перевірні символи по рядках за формулою (1) (див. табл. 1). 3 виходу внутрішнього кодера $y_{1}$ кодові слова поступають у буфер. 3 буфера кодові слова зчитуються по стовпцях і поступають у зовнішній кодер $y_{2}$, де обчислюють перевірні символи по стовпцях за формулою (2).

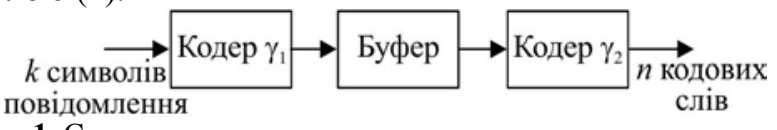

Рис. 1. Структурна схема кодера

Виявлення помилок відбувається на основі аналізу синдрому, який обчислюють як різницю перевірних символів, обчислених у кодері та декодері. Обчислення синдрому по рядках:

$$
\delta_{i}=\left\{\left(f_{j k}^{\prime}(x)-f_{j k}(x)\right) \bmod P, j=\overline{1, l}\right\} .
$$

Обчислення синдрому по стовпцях:

$$
\delta_{j}=\left\{\left(f_{l i}^{\prime}(x)-f_{l i}(x)\right) \bmod P, i=\overline{1, k}\right\},
$$

де: $f_{j k}^{\prime}(x), f_{l i}^{\prime}(x)$ - перевірні символи, обчислені в декодері за прийнятими даними.

Якщо $\delta_{i}=0, \delta_{j}=0$ - помилки немає.

Якщо $\delta_{i} \neq 0, \delta_{j} \neq 0$ - наявна помилка.

Позицію спотвореного символу визначають за значенням синдромів, які на перетині рядка і стовпця не дорівнюють нулю.

Для виправлення помилки в одному символі необхідно розв'язати таке рівняння:

$$
v_{i}\left(x_{i}^{\prime}-x_{i}\right)=\delta_{i}(\bmod P) .
$$

Якщо синдроми $\delta_{i} \neq 0, \delta_{j} \neq 0$ не дорівнюють нулю у двох і більше рядках або стовпцях, то це означає, що помилки відбулися у двох і більше символах. При цьому, якщо синдром $\delta_{j} \neq 0$ у двох стовпцях, то це означає, що спотворені два символи в рядку. Ненульові значення синдромів визначають позиції спотворених символів.

Виправлення помилок у двох інформаційних символах. Аналіз синдрому по рядках і стовпцях дає змогу виявити позиції спотворених символів. Для їх виправлення необхідно розв'язати такі рівняння:

$$
\begin{gathered}
v_{i}\left(x_{i}^{\prime}-x_{i}\right)+v_{t}\left(x_{t}^{\prime}-x_{t}\right)=\delta_{i j}(\bmod P) ; \\
v_{i} x_{i}^{\prime}-v_{i} x_{i}+v_{t} x_{t}^{\prime}-v_{t} x_{t}=\delta_{i j}(\bmod P) ; \\
-v_{i} x_{i}-v_{t} x_{t}=\left(\delta_{i j}-v_{i} x_{i}^{\prime}-v_{t} x_{t}^{\prime}\right)(\bmod P) ; \\
v_{i} x_{i}+v_{t} x_{t}=\left(v_{i} x_{i}^{\prime}+v_{t} x_{t}^{\prime}-\delta_{i j}\right)(\bmod P),
\end{gathered}
$$

де $i, t$ - позиції спотворених символів.

Замінимо праву частину на $c$

$$
v_{i} x_{i}+v_{t} x_{t}=c(\bmod P) \text {. }
$$

Відомо: якщо $\operatorname{gcd}\left(v_{i}, v_{t}\right)$, тобто $v_{i}$ i $v_{t}$ взаємно прості числа, то рівняння (5) має розв'язок у цілих числах.

Розв'яжемо рівняння (5) відносно одного 3 невідомих. Виразимо $x_{i}$ через $x_{t}$ :

$$
x_{i}=\left(\frac{c-v_{t} x_{t}}{v_{i}}\right)(\bmod P) .
$$

Якщо $0 \leq x_{i}<2^{m}$ i $0 \leq x_{t}<2^{m}$, то, підставивши в рівняння (6) замість $x_{t}$ значення від 0 до $2^{m}$, знаходимо множину розв'язків $x_{i}, 3$ яких тільки один із знайдених розв'язків буде цілим числом.

За мінімальної кодової відстані кодів $y_{1}$ i $y_{1}$, що дорівнює $d_{1}$ i $d_{2}$ відповідно то мінімальна кодова відстань двовимірного коду $\gamma$ рівна $d_{1} \times d_{2}$. Отже, якщо коди $y_{1}$ i $y_{2}$ виправляють $t_{1}$ i $t_{2}$ помилки відповідно, то двовимірний код виправляе $2 t_{1} t_{2}+t_{1}+t_{2}+1$ помилок.

Враховуючи, що модулярний код може виправляти дві помилки, якщо відомо їх розташування, то максимальна довжина пакету помилок становить $b=3 k-2$ символи, під час розміщення спотворених символів у двох рядках і одному стовпці, або в двох стовпцях і одному рядку (рис. 2).

\begin{tabular}{|c|c|c|c|c|c|c|c|}
\hline$*$ & $*$ & $*$ & $*$ & $*$ & $*$ & $*$ & $*$ \\
\hline$*$ & $*$ & $*$ & $*$ & $*$ & $*$ & $*$ & $*$ \\
\hline & $*$ & & & & & & \\
\hline & $*$ & & & & & & \\
\hline & $*$ & & & & & & \\
\hline & $*$ & & & & & & \\
\hline & $*$ & & & & & & \\
\hline & $*$ & & & & & & \\
\hline
\end{tabular}

Рис. 2. Приклад розміщення пакету помилок максимальної довжини

Проте цей код не зможе виправити пакет помилок зі шести символів, які розміщені на перетині трьох рядків і трьох стовпців (рис. 3).

\begin{tabular}{|l|c|c|c|c|c|c|c|}
\hline & & & & & & & \\
\hline & $*$ & $*$ & $*$ & & & & \\
\hline & $*$ & $*$ & $*$ & & & & \\
\hline & $*$ & $*$ & $*$ & & & & \\
\hline & & & & & & & \\
\hline & & & & & & & \\
\hline & & & & & & & \\
\hline & & & & & & & \\
\hline
\end{tabular}

Рис. 3. Приклад розміщення пакету помилок

Алгоритм двовимірного виявлення та виправлення помилок. Алгоритм складається з блоку введення даних, де вводимо взаємно прості коефіцієнти $v_{i}$, значення модуля $P$ та інформаційні символи $x_{i}$. Далі обчислюємо синдроми по рядках та по стовпцях за формулами (див. вирази (1), (2)). Якщо значення синдрому $\delta_{i}=0, \delta_{j}=0$, то помилки не виявлено, а якщо $\delta_{i} \neq 0$, $\delta_{j} \neq 0$ або якщо хоч в одному із синдромів $\delta_{i}=0, \delta_{j} \neq 0$ та $\delta_{i} \neq 0, \delta_{j}=0$, то помилку виявлено і переходимо до iii виправлення. Для виправлення помилки в одному символі для кожного рядка розв'язуємо рівняння (3), де: 
$v_{i}$ - взаємно прості коефіцієнти, $x_{i}^{\prime}-$ прийняте повідомлення та $x_{i}$ - повідомлення, яке відправляли. Після обчислення рівняння (3) для всіх рядків, перевіряємо значення синдрому при: $\delta_{i} \neq 0, \delta_{j}=0$ - помилки є в стовпцях, які виправляємо за формулою (див. (4)) та підставляємо значення розв'язків у матрицю; $\delta_{i}=0, \delta_{j} \neq 0$ - помилки є в рядках, які виправляємо за формулою (див. (4)). Перевіряємо ще раз, і якщо значення синдрому $\delta_{i}=0, \delta_{j}=0$, то помилки виправлені, а якщо значення синдрому $\delta_{i} \neq 0, \delta_{j} \neq 0-$ то помилок більше, ніж алгоритм може виправити.

Результати дослідження. Побудуємо двовимірний код на основі модулярного коригувального коду при $k$ $=8, l=8$, розрядність інформаційних символів $m=4$, модуль $P=1021$, коефіцієнти: $v_{1}=13, v_{2}=17, v_{3}=19$, $v_{4}=23, v_{5}=29, v_{6}=31, v_{7}=37, v_{8}=43$ (табл. 2).

Табл. 2. Модулярний двовимірний код на виході передавача

\begin{tabular}{|c|c|c|c|c|c|c|c|c|c|}
\hline & $x_{1}$ & $x_{2}$ & $x_{3}$ & $x_{4}$ & $x_{5}$ & $x_{6}$ & $x_{7}$ & $x_{8}$ & $\#$ \\
\hline \multirow{6}{*}{} & 3 & 4 & 9 & 10 & 12 & 14 & 6 & 8 & 835 \\
\cline { 2 - 11 } & 11 & 14 & 15 & 0 & 1 & 2 & 7 & 4 & 167 \\
\cline { 2 - 10 } & 4 & 7 & 2 & 15 & 12 & 3 & 11 & 13 & 940 \\
\cline { 2 - 10 } & 1 & 2 & 3 & 4 & 7 & 8 & 10 & 0 & 1017 \\
\cline { 2 - 10 } & 2 & 4 & 6 & 7 & 1 & 8 & 11 & 15 & 677 \\
\cline { 2 - 10 } & 5 & 4 & 1 & 3 & 7 & 9 & 7 & 3 & 70 \\
\cline { 2 - 10 } & 3 & 8 & 10 & 14 & 12 & 5 & 6 & 7 & 692 \\
\cline { 2 - 10 } & 12 & 11 & 7 & 4 & 3 & 2 & 1 & 8 & 77 \\
\hline \#\# & 144 & 457 & 334 & 472 & 360 & 218 & 416 & 529 & \\
\hline
\end{tabular}

Примітка: перевірні числа по рядках (\#) і стовпцях (\#\#).

Розглянемо алгоритм виправлення помилок за максимальної кількості спотворених символів (табл. 3).

Табл. 3. Модулярний двовимірний код на вході приймача

\begin{tabular}{|c|c|c|c|c|c|c|c|c|c|}
\hline & $x_{1}$ & $x_{2}$ & $x_{3}$ & $x_{4}$ & $x_{5}$ & $x_{6}$ & $x_{7}$ & $x_{8}$ & $\#$ \\
\hline \multirow{6}{*}{} & $\mathbf{1 2}^{*}$ & $\mathbf{1 1}^{*}$ & $\mathbf{6}^{*}$ & $\mathbf{5}^{*}$ & $\mathbf{3}^{*}$ & $\mathbf{1}^{*}$ & $\mathbf{9}^{*}$ & $\mathbf{7}^{*}$ & 303 \\
\cline { 2 - 10 } & $\mathbf{4}^{*}$ & $\mathbf{1}^{*}$ & $\mathbf{0}^{*}$ & $\mathbf{1 5}^{*}$ & $\mathbf{1 4}^{*}$ & $\mathbf{1 3}^{*}$ & $\mathbf{8}^{*}$ & $\mathbf{1 1}^{*}$ & 971 \\
\cline { 2 - 10 } & 4 & 7 & $\mathbf{1 3}^{*}$ & 15 & 12 & 3 & 11 & 13 & 128 \\
\cline { 2 - 10 } & 1 & 2 & $\mathbf{1 2}^{*}$ & 4 & 7 & 8 & 10 & 0 & 167 \\
\cline { 2 - 10 } & 2 & 4 & $\mathbf{9}^{*}$ & 7 & 1 & 8 & 11 & 15 & 734 \\
\cline { 2 - 10 } & 3 & 4 & $\mathbf{1 4}^{*}$ & 3 & 7 & 9 & 7 & 3 & 317 \\
\cline { 2 - 10 } & 12 & 11 & $\mathbf{8}^{*}$ & 4 & 3 & 2 & 1 & 8 & 96 \\
\hline$\# \#$ & 142 & 327 & 804 & 662 & 464 & 236 & 472 & 635 & \\
\hline
\end{tabular}

Примітка: перевірні числа по рядках (\#) і стовпцях (\#\#), * - спотворені символи.

Як видно 3 табл. 4, спотворені символи є в усіх рядках та стовпцях. Алгоритм виявлення та виправлення помилок складається 3 таких кроків:

Табл. 4. Значення синдрому по рядках і стовпцях

\begin{tabular}{|c|c|}
\hline Синдром по рядках, $\delta_{i}$ & Синдром по стовпцях, $\delta_{j}$ \\
\hline 489 & 1019 \\
\hline 804 & 891 \\
\hline 209 & 470 \\
\hline 171 & 190 \\
\hline 57 & 104 \\
\hline 247 & 18 \\
\hline 926 & 56 \\
\hline 19 & 106 \\
\hline
\end{tabular}

1. Перевіряємо чи є рядки з однією помилкою. Для цього послідовно розв'язуємо рівняння (3) для кожного рядка. Результати розв'язку наведено в табл. 5. Як видно з цієї таблиці, знайдені розв'язки - цілі числа в заданому діапазоні (0-15) свідчать про те, що спотворений символ $x_{2}$ у $3-8$ рядках.
Табл. 5. Результати розв'язку рівняння (3)

\begin{tabular}{|c|c|c|c|c|c|c|c|c|}
\hline \multirow{2}{*}{ № } \\
рядка & \multicolumn{7}{|c|}{ Інформаційний символ } \\
\cline { 2 - 9 } & $x_{1}$ & $x_{2}$ & $x_{3}$ & $x_{4}$ & $x_{5}$ & $x_{6}$ & $x_{7}$ & $x_{8}$ \\
\hline 1 & 52,92 & 42,29 & 34,00 & 28,13 & 21,34 & 18,16 & 23,37 & 19,37 \\
\hline 2 & 20,69 & 13,76 & 11,42 & 24,43 & 21,48 & 20,00 & 13,86 & 16,04 \\
\hline 3 & 66,46 & 54,76 & $\mathbf{2}$ & 5,91 & 4,79 & 29,19 & 5,35 & 8,13 \\
\hline 4 & 66,38 & 52,00 & $\mathbf{3}$ & 40,96 & 1,10 & 2,48 & 5,37 & 19,76 \\
\hline 5 & 76,15 & 0,65 & $\mathbf{6}$ & 4,52 & 34,24 & 6,16 & 9,46 & 13,67 \\
\hline 6 & 64,54 & 49,53 & $\mathbf{1}$ & 36,65 & 33,69 & 1,04 & 0,32 & 21,00 \\
\hline 7 & 10,31 & 13,59 & $\mathbf{1 0}$ & 18,13 & 15,28 & 8,06 & 8,56 & 9,21 \\
\hline 8 & 10,54 & 9,88 & $\mathbf{7}$ & 3,17 & 2,34 & 1,39 & 0,48 & 7,56 \\
\hline
\end{tabular}

2. Підставивши обчислені значення в табл. 2, отримаємо нову таблицю синдромів (табл. 6).

Табл. 6. Таблиця синдромів після часткового виправлення помилок

\begin{tabular}{|c|c|}
\hline Синдром по рядках, $\delta_{i}$ & Синдром по стовпцях, $\delta_{j}$ \\
\hline 489 & 1019 \\
\hline 804 & 891 \\
\hline 0 & 727 \\
\hline 0 & 190 \\
\hline 0 & 104 \\
\hline 0 & 18 \\
\hline 0 & 56 \\
\hline 0
\end{tabular}

Аналіз табл. 6 показує, що помилки $є$ в усіх стовпцях, але тільки у двох рядках, тобто спотворені всі символи в першому і другому рядку. Виправлення помилок у двох символах здійснюємо за допомогою рівняння (4).

Для виправлення помилок у символах, розміщених у першому стовпці, підставимо числові значення у рівняння (4) і отримаємо:

$$
\begin{gathered}
13\left(12-x_{1}\right)+17\left(4-x_{2}\right)=1019(\bmod 1021), \\
13 x_{1}+17 x_{2}=226(\bmod 1021) .
\end{gathered}
$$

Розв'язавши рівняння (4), для кожного стовпця матриці знайдемо правильні інформаційні символи (табл. 7). Як видно з цієї таблиці, знайдені розв'язки рівняння (7) однозначно забезпечують виправлення помилок у 22 символах вхідного повідомлення. Отже, розроблений код дає змогу виправляти пакети помилок із максимальною довжиною $b=3 k-2$ символів, під час розміщення спотворених символів у двох рядках і одному стовпці або у двох стовпцях і одному рядку. При цьому забезпечує швидкість коду $R_{1}=k_{1} / n_{1}=0,62$, при $k=8, \quad m_{1}=4, \quad P=1021, \quad k_{1}=k \cdot k \cdot m_{1}=256$, $\left.n_{1}=2 \cdot k \cdot\right] \log _{2} P\left[=160, \quad n_{1}=k_{1}+r_{1}=416 \quad\right.$ та $\quad R_{2}=k_{2} / n_{2}=0,67$ при $m_{2}=8, k_{2}=512, n_{2}=768$. Відносна надлишковість коду дорівнює: $r=\left(1-R_{1}\right) \cdot 100=38 \%$.

Табл. 7. Розв'язки рівняння (7)

\begin{tabular}{|c|c|c|c|c|c|c|c|c|}
\hline & \multicolumn{7}{|c|}{ Інформаційнй символ } \\
\hline$x_{2}$ & $x_{11}$ & $x_{12}$ & $x_{13}$ & $x_{14}$ & $x_{15}$ & $x_{16}$ & $x_{17}$ & $x_{18}$ \\
\hline 0 & 17,38 & 22,31 & 28,62 & $\mathbf{1 0}$ & 13,31 & 16,62 & 15,15 & 13,23 \\
\hline 1 & 16,08 & 21 & 27,31 & 8,69 & $\mathbf{1 2}$ & 15,31 & 13,85 & 11,92 \\
\hline 2 & 14,77 & 19,69 & 26 & 7,38 & 10,69 & $\mathbf{1 4}$ & 12,54 & 10,62 \\
\hline 3 & 13,46 & 18,38 & 24,69 & 6,08 & 9,38 & 12,69 & 11,23 & 9,31 \\
\hline 4 & 12,15 & 17,08 & 23,38 & 4,77 & 8,08 & 11,38 & 9,92 & $\mathbf{8}$ \\
\hline 5 & 10,85 & 15,78 & 22,08 & 3,46 & 6,77 & 10,08 & 8,62 & 6,69 \\
\hline 6 & 9,54 & 14,46 & 20,77 & 2,15 & 5,46 & 8,77 & 7,31 & 5,38 \\
\hline 7 & 8,23 & 13,15 & 19,46 & 0,85 & 4,15 & 7,46 & $\mathbf{6}$ & 4,08 \\
\hline 8 & 6,92 & 11,84 & 18,15 & $-0,46$ & 2,85 & 6,15 & 4,69 & 2,77 \\
\hline 9 & 5,62 & 10,54 & 16,85 & $-1,77$ & 1,54 & 4,85 & 3,38 & 1,46 \\
\hline 10 & 4,31 & 9,23 & 15,54 & $-3,08$ & 0,23 & 3,54 & 2,08 & 0,15 \\
\hline 11 & $\mathbf{3}$ & 7,92 & 14,23 & $-4,38$ & $-1,08$ & 2,23 & 0,77 & $-1,15$ \\
\hline 12 & 1,69 & 6,62 & 12,92 & $-5,69$ & $-2,38$ & 0,92 & $-0,54$ & $-2,46$ \\
\hline 13 & 0,38 & 5,31 & 11,62 & $-7,00$ & $-3,69$ & $-0,38$ & $-1,85$ & $-3,77$ \\
\hline 14 & $-0,92$ & $\mathbf{4}$ & 10,31 & $-8,31$ & $-5,00$ & $-1,69$ & $-3,15$ & $-5,08$ \\
\hline 15 & $-2,23$ & 2,69 & $\mathbf{9}$ & $-9,62$ & $-6,31$ & $-3,00$ & $-4,46$ & $-6,38$ \\
\hline
\end{tabular}


Висновки. Запропоновано метод виправлення пакетів помилок на основі модулярних коригувальних кодів, який забезпечує ефективне виправлення помилок завдяки послідовній перевірці по рядках та стовпцях матриці даних. Розроблено алгоритм виявлення та виправлення випадкових однократних помилок та пакетів помилок максимальною довжиною $b=3 k-2$, за швидкості коду $R=0,67$. Враховуючи низьку складність реалізації алгоритму декодування, цей коригувальний код планують використати для підвищення надійності передачі даних у безпровідних сенсорних мережах.

\section{Перелік використаних джерел}

Aditya Vempaty, Yunghsiang S. Han, Pramod K. Varshney (2014). Target Localization in Wireless Sensor Networks using Error Correcting Codes. IEEE Transactions on Information Theory, 60(1), 697-712. https://doi.org/10.1109/TIT.2013.2289859

Alrajeh, N., et al. (2015). Error Correcting Codes in Wireless Sensor Networks: An Energy Perspective. Applied Mathematics \& Infor$\begin{array}{lll}\text { mation } & \text { Sciences, } & 9(2),\end{array}$ https://doi.org/10.1109/TIT.2013.2289859

Bleikhut, R. (1986). Teoriia i praktika kodov, kontroliruiushhikh oshibki (Grushko, I. I., Blinovskii, V. M. Trans. from English). Zigangirova, K. Sh. (Ed.). Moscow: Mir. 576 p. [in Russian].
Fatt, Tay Thian, \& ChipHong, Chang. (2014). A new algorithm for single residue digit error correction in Redundant Residue Number System. Circuits and Systems, ISCAS, (pp. 1748-1751), IEEE International http://doi.org/10.1109/ISCAS.2014.6865493

Jun, Su, \& Yatskiv, V. (2013). Method and Device for Image Coding \& Transferring Based on Residue Number System. Sensors \& Transducers Journal, 18, Special Issue, 60-65.

Morelos-Saragosa, R. (2005). Iskusstvo pomekhoustoichivogo kodirovaniia. Metody, algoritmy, primenenie. Moscow: Tekhnosfera. 320 p. [in Russian].

Sieck, J., Yatskiv, V., Sachenko, A., \& Tsavolyk, T. (2015). Two-Dimensional Error Control Based on Modular Corrective Codes. International Journal of Computing, 14(4), 208-213.

Yatskiv, V., Yatskiv, N., Jun, Su, Sachenko, A., \& Zhengbing, Hu. (2013). The Use of Modified Correction Code Based on Residue Number System in WSN. Proceedings of the 7-th 2013 IEEE International Conference on Intelligent Data Acquisition and Advanced Computing Systems, 1, 513-516, IDAACS'2013, Berlin, Germany.

Yatskiv, V., Yatskiv, N., Sachenko, A., \& Jun, Su (2014). CPLD Encoder and Decoder for Modified Correction Codes Based on Residue Number System. Modern Problems of Radio Engineering, Telecommunications, and Computer Science. Proceedings of the International Conference (TCSET'2014), (pp. 492-493), February 25 March 1, Ukraine. Lviv-Slavske.

Т. Г. Цаволик, В. В. Яцкив

Тернопольский национальный экономический университет, г. Тернополь, Украина

\section{ИСПРАВЛЕНИЕ ПАКЕТОВ ОШИБОК НА ОСНОВЕ МОДУЛЯРНЫХ КОРРЕКТИРУЮЩИХ КОДОВ}

Предложен метод исправления пакетов ошибок на основе модулярного корректирующего кода для повышения надежности передачи данных в беспроводных сенсорных сетях. Для борьбы с пакетами ошибок разработаны различные многомерные (каскадные, итеративные) коды. Принцип работы данных кодов заключается в последовательном использовании двух уровней кодирования и декодирования данных. При этом на каждом уровне кодирования могут использоваться одинаковые по типу и корректирующей способностью коды или разные. Преимуществом многомерных кодов является их высокая корректирующая способность, а недостатком - высокая избыточность. Разработана двумерная схема контроля ошибок на основе модулярного корректирующего кода. Модульные корректирующие коды относятся к символьным кодам, характеризуются низкой избыточностью, позволяют эффективно выявлять и исправлять единичные символьные ошибки. Принцип формирования проверочных символов в двумерном модульном коде заключается в следующем. Сначала производится исчисление проверочных символов по строкам матрицы данных. На следующем шаге вычисляются проверочные символы по столбцам данных. Разработан алгоритм обнаружения и исправления случайных однократных ошибок и пакетов ошибок максимальной длиной $b=3 k-2$. Проведены экспериментальные исследования по выявлению и исправлению ошибок в пакете данных. Показано минимальную и максимальную длину и структуру ошибок, которую может исправить данный код. Учитывая низкую сложность реализации алгоритма декодирования данный корректирующий код планируется использовать для повышения надежности передачи данных в беспроводных сенсорных сетях.

Ключевые слова: модульные корректирующие коды; беспроводные сенсорные сети; двумерный код; пакет ошибок.

T. H. Tsavolyk, V. V. Yatskiv

Ternopil National Economic University, Ternopil, Ukraine

\section{BURST ERROR-CORRECTING CODES BASED ON MODULAR CORRECTING CODES}

The authors have developed burst error-correcting method based on modular correcting codes. We have also designed error correcting algorithm for increasing data transfer reliability in the wireless sensor networks. Multidimensional codes (cascaded, iterated codes, product codes) were developed to deal with bursts of errors. The principle of these codes is the consistent use of two levels of encoding and decoding data. The codes with both same or different type and correcting ability can be used for each coding level. The advantage of multidimensional codes is high correction capability, and the disadvantage is high redundancy. At this work we developed two-dimensional error control scheme based on modular correction code. Modular correcting codes are non-binary codes that work with symbols composed of several bits characterized by low redundancy and allow effectively detecting and correcting any single errors. The principle of formation of check symbols in two-dimensional modular code is as follows. Firstly, the calculation of the check characters in the rows of the matrix of data is carried out. At the next stage, we calculated check symbols in the data columns. At that check symbols are calculated in the data rows and data columns can be transmitted with both data and individual packages. We developed error detection and correction algorithm for random single errors and error bursts with the length of $b=3 k-2$. Experimental researches on detection and correction of error packages have been carried out. Finally, we calculated the syndrome as the difference between the check symbols calculated in the encoder and decoder. The position of the distorted symbol is determined by the value of the syndromes, which are not equal to zero at the intersection of the row and the column. If syndromes are not equal to zero in two or more rows or columns, then the errors occur in two or more symbols. If the syndrome in two columns - this means that the two characters in the row are distorted. Non-zero values of syndromes determine the positions of distorted symbols. Thus, the minimum and maximum length and structure of errors that can be corrected are shown. Due to low complexity of implementation of decoding algorithm this code can be used for increasing of data transmission reliability in wireless sensor networks.

Keywords: modular correction codes; wireless sensor networks; two-dimensional code; packet of errors. 